\title{
Drama-based activities for STEM education: encouraging scientific aspirations and debunking stereotypes in secondary school students in Spain and the UK
}

Villanueva Baselga, Sergio ${ }^{1,2}$, Marimon Garrido, Oriol ${ }^{3}$, González Burón, Helena ${ }^{3}$

${ }^{1}$ Department of Library, Information and Communication. Universitat de Barcelona

${ }^{2}$ Centre for Research in Information, Communication and Culture (CRICC), Universitat de Barcelona

${ }^{3}$ Big Van Ciencia

\begin{abstract}
This study presents findings from testing an innovative student-centred drama-based teaching methodology for Science, Technology, Engineering and Maths (STEM) disciplines for secondary school students. The method, based on performances, was tested in two case studies, Spain and the UK, on a sample of 2,089 students. These performances have been shown to be an effective way of generating a two-way dialogue between students and researchers, and prompting student reflections about researchers as role models, gender inequalities in science, and ethical issues in STEM careers and scientific research. Furthermore, they have enhanced young people's positive attitudes and interest in science, scientists and scientific careers and have debunked science-related stereotypes. This indicates that the performances evaluated in this study are supporting the aspirations of young people, but not limiting their inclination to critically assess the relative benefits and risks of scientific development for themselves.
\end{abstract}

Keywords: drama-based education ' science education ' student-centred pedagogy' scientific vocations $\cdot$ responsible research and innovation

\section{INTRODUCTION}

In the current European socio-economic and political context, motivational and structural barriers constrain individuals' interest and active involvement in science and technology. The need to address the challenge of engaging the public in science is even more urgent in the case of young people. Their considerable disenchantment with science and technology represents a critical limitation on European society's capacity to ensure its future capacity for innovation, excellence and competitiveness (Osborne and Dillon, 
2008). Results from the Flash Eurobarometer (2008) on "Young People and Science" showed that less than a third of respondents had an interest in studying engineering (28\%), natural sciences $(25 \%)$ or mathematics $(24 \%)$, compared to $36 \%$ and $39 \%$ who would consider studying economics or social sciences, respectively. In the UK, for instance, only $4 \%$ of respondents said they would definitely study natural sciences. The survey findings also suggested significant gender differences related to future career preferences (Littledyke, 2008), as boys were more interested in engineering and mathematics than girls, who generally argued that they did not have the skills to study engineering, biology or medicine. Similar data is obtained in Spain (Sainz, 2011). Although science itself involves curiosity, creativity, and imagination, European young people, especially girls, still perceive scientific complexity as a barrier and scientific careers as useless and unprofitable, which could discourage them from pursuing studies in scientific fields (Khale et al., 1993).

In recent decades, numerous authors have warned of the decline of scientific vocations in the European context (Convert and Gugenheim, 2005; Rocard et al., 2007; OECD, 2008). This disaffection is being increasingly attributed to pedagogical issues, as the hypothesis of a relationship between the poor image of science in society and the lack of young people pursuing scientific vocations is being abandoned (Sjøberg and Schreiner 2007; Fouad et al., 2010; Regan and DeWitt, 2015; Sheldrake, 2016). In fact, many authors have reported evidence of a generally positive picture of science and the scientific professions among students. Jenkins and Nelson (2005) have used the paradox "important, but not for me" to explain the fact that, in practice, fewer and fewer students opt to pursue scientific careers. A substantial body of research has explored the interrelationships between aspirations and structural factors such as gender, ethnicity and social class (Eccles, 1994; Francis, 2002; Aschbacher et al., 2010; St Clair \& Benjamin, 2011; Riegle-Crumb et al., 2011), making room for a deeper discussion about the need for intersectional analysis, in which teaching pedagogies are the centre of attention. 
Arts-based educational approaches have been used in the last few decades both in education research-for instance, under the label "Arts-based Educational Research" (Barone and Eisner, 2012) — and more specifically in science education (Metcalfe et al., 1984; Ødegaard, 2003; Aubusson and Fogwill, 2006; Dorion, 2009). These approaches are characterized by the inclusion of elements from the arts (performance, literary writing, music, dance, storytelling, visual art and other mediums) in different stages of the research or educational process in order to express human experience, explore different forms of representation and convey meaning. Arts-based practices have been identified as particularly useful for projects that aim to describe, explore, or discover (Leavy, 2009), all of which are important features of a learning process. Specifically, applied dramareferring to dramatic activities that exist primarily outside conventional mainstream theatre institutions and have objectives that go beyond the artistic to include educational, social and political aims - has participatory, dialogic and dialectic qualities that constitute effective and democratic ways of learning (Nicholson, 2005). The integration of both rational and emotional dimensions within dramatic activities provides a rich source of individual and collective experimentation and exploration (Baraúna Teixera and Motos Teruel, 2009).

Furthermore, dramatic activities have been identified as particularly useful teaching and learning strategies for integrating affective and cognitive education into informed action (Littledyke, 2008). A recent meta-analysis (Lee et al, 2015) showed that drama-based activities have a significant impact on achieving outcomes in educational settings, especially if activities (a) were led by a classroom teacher or researcher rather than a teaching artist, (b) included more than five lessons, and (c) was integrated into English language arts or science curriculum compared to other domains As a collaborative art form, applied drama embodies a pedagogy designed to encourage interactivity and collaboration, emphasizing the centrality of the student in the pedagogical process. As a practice, knowledge in drama is embodied, culturally located and produced through interactions with others, generating new forms of social and cultural capital (Tveita, 1998; McNaughton, 2004). Engagement through arts-based approaches may support the 
integration and mobilization of multiple kinds of knowledge, imagination, and intelligences (including emotional, social or experiential) (Leavy, 2015; Rathwell and Armitage, 2016). Based on this insight, a limited number of studies have researched the impact that drama-based activities have on science education both at primary (Varelas et al, 2010) and at secondary levels (Bailey and Watson, 1998).

The potential of applied drama in science education to facilitate an understanding of STEM concepts and reflect on the role and use of science in society lies not only in communicating scientific concepts and bringing them to life, but also in addressing the nature of science as a transformative learning process embedded in a certain societal context. In this sense, arts-based methods in science education might operate through the inclusion of values and tangential social elements while teaching scientific concepts. The use of arts-based methods for debunking stereotypes has shown its effectiveness in a number of fields, such as in challenging gender bias in the gaming industry (Shen at al., 2016) or in sex education in secondary schools (Simons, 2011). In this sense, arts-based methods might be effective as a device for debunking science-related stereotypes. With this in mind, the hypothesis underpinning this study is that arts-based methods help to trigger emotions that facilitate the deconstruction of false myths and stereotypes related to scientific research and activity.

This study presents the findings from a project to test a new kind of student-centred drama-based teaching methodology called PERSEIA (PERformance-based Science Education Innovative Activities), aimed at fostering student engagement with STEM at selected secondary schools in Spain and the United Kingdom. In order to connect with the emotions and personal concerns of young people, PERSEIA challenges stereotypes associated with science, explores ethical issues related to scientific research, tackles gender barriers in STEM university programs and relates scientific knowledge with opportunities in the labour market. PERSEIA was developed within the framework of the European Commission Horizon 2020 project PERFORM (www.perform-research.eu), explained in-depth elsewhere (Ruiz-Mallén et al., 2018), based on drama-based teaching 
experiences for science that have been previously reported in both countries (for Spain check Dopico et al, 2015, for UK Lee et al, 2015).

\section{METHODS}

\section{PERSEIA delivery}

PERSEIA is defined as a human-centred, arts-based approach to science education that uses theatre plays on the premise that to encourage scientific aspirations in young people it is not enough merely to talk about science in a funny way; we also need to include the human dimension of science. Within the research project PERFORM, a toolkit to create PERSEIA was developed, and resulting PERSEIA were piloted in secondary schools in Spain and UK. The schools were selected in these two countries because they were the only, within the PERFORM consortium, that hosted both academic and education partners). PERSEIA are based on two specific theatrical forms: stand-up comedy (used in the Spanish case), and science busking (in the UK). Scientific stand-up comedy involves individual monologues that use jokes and humour to deconstruct clichés and stereotypes and to explain everyday scientific activities or recent scientific discoveries. On the other hand, Street Science busking is an adaptation of street theatre in which spectacular and surprising scientific experiments are performed in the street and in public places, followed by explanations. In addition, PRESEIA adapts stand-up or busking scripts to key agendas of Responsible Research and Innovation (Owen et al., 2012; Heras and Ruiz-Mallén, 2017), following the recommendations listed in table 1.

Table 1: Guidelines to adapt theatre scripts to PERSEIAA

\section{STEM JOBS}

Highlight that Science and STEM jobs are everywhere (including in private companies):

$\checkmark$ An excavation, an electoral survey, an architectural studio, an aeroplane, an engineering company, the zoo, a football team, Science Communication

Highlight aspects of STEM jobs that young people consider positive: 


\begin{tabular}{|l}
$\checkmark$ \\
Travelling, helping others, flexible schedule, hands-on activities, fighting \\
injustice
\end{tabular}

Highlight that some highly esteemed jobs are actually STEM jobs:

$\checkmark$ Architect, airline pilot. Take into account local particularities

\section{SCIENTIFIC STEREOTYPES}

Highlight positive stereotypes:

$\checkmark$ External recognition, imaginative, self-confident, motivated to acquire knowledge, long-term goal. "Knowledge gives you power: the more you know, the fewer lies you will believe."

Challenge negative stereotypes:

$\checkmark$ Freaky, nerdy, boring, bad partner or parent, social rejection, socially inept, always 'ON' and in their own world

\section{ETHICS IN RESEARCH}

Highlight that scientists do not try to play God, as all new discoveries are under ethical control:

$\checkmark$ GMO, Artificial Intelligence/Robots, medical advances (cloning, genetic modifications in humans)

Highlight that research is not only conducted to generate useful knowledge from a human interest point of view. Ethical standards promote research in basic science such as:

$\checkmark$ Improving the environment

$\checkmark$ Basic knowledge to improve our understanding of nature

$\checkmark$ Ensure animal rights in animal testing

\section{EU SOCIETAL CHALLENGES}

Use the EU Societal Challenges that students have considered of interest as a hook:

$\checkmark$ Health, demographic change and wellbeing

$\checkmark$ Climate action and the environment

$\checkmark$ Secure societies, freedom and security

Take into account the local particularities:

GENDER ISSUES IN STEM 


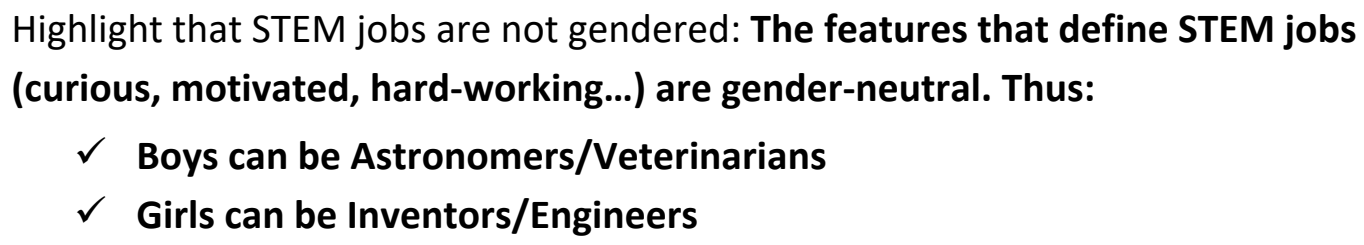

Give special attention to girls in engineering:

$\checkmark$ To strengthen girls' self-confidence to pursue studies in engineering/maths

$\checkmark$ To highlight the social outreach of engineering

Identify actual, important women scientists as role models. To give special mention to physicists, engineers and computational scientists.

\section{General recommendations (GR)}

Allow students to ask questions or to give their opinion during/after the PERSEIA.

Show a short video ( 3 to 5 minutes) talking about a scientific topic.

From December 2016 to June 2017, PERSEIA were delivered in 18 secondary schools, 9 in each country, inside the classrooms, to school groups between 15 and 200 students, amounting to a total of 2,089 students. These schools were located in low-income (5 in Spain, 4 in UK) and middle-income areas (4 in Spain, 5 in UK). The PERFORM project launched an open call to schools in the area of Barcelona (ES) and Bristol (UK) and the schools were selected regarding to their willingness to incorporate innovative teaching methods in their STEM courses, and the socioeconomic level of students. In Spain, PERSEIA took the form of stand-up comedy sketches that were presented in the school auditoriums so that they could reach a larger number of students $(1,823$ in total). In the UK, PERSEIA were delivered in the form of science busking shows, which necessarily involved fewer students. As a result, the UK version of PERSEIA reached 266 students.

\section{PERSEIA evaluation}

To evaluate the impact of the PERSEIA delivered to secondary school students, a repeated impact evaluation study was developed. This was conducted using ex-ante and ex-post self-administered questionnaires in both English (in the UK) and Spanish (in Spain) in all the participant schools. The questionnaire was administered by teachers in 
computer labs in schools. The survey combines Likert scales with some open-ended items. The main objectives of the questionnaire were (i) to identify perceptions and attitudes of student audiences towards the PERSEIA (enjoyment, interest, value, competence), and (ii) to explore whether the performances are able to generate a two-way dialogue between students and researchers and stimulate students' reflections on the different topics PERSEIA aimed to include (i.e. gender inequality and barriers to girls in STEM; science-related stereotypes; ethical issues in scientific research; the role of entrepreneurial and multidisciplinary research careers in the labour market). The rates of response are shown in table 2. A total of 1,221 answers were collected. All students participating in the evaluation were authorized by their legal representatives by a signed consent to participate in the studio.

Table 2: Rate of response in Spain and UK for the ex-ante and ex-post questionnaires

\begin{tabular}{|llllll|} 
& & \multicolumn{2}{c}{ PRE-PERSEIA } & \multicolumn{2}{c|}{ POST-PERSEIA } \\
\hline Spain & Attendants & Respondents & \% Girls & Respondents & \%Girls \\
\hline UK & 1,823 & $43.1 \%(785)$ & 50.8 & $62.4(490)$ & 49.8 \\
\hline TOTAL & 266 & $70.7 \%(188)$ & 47.9 & $58.5 \%(110)$ & 47.3 \\
\hline
\end{tabular}

\section{RESULTS}

Students' STEM perceptions

To analyse students' perceptions towards STEM careers, the questionnaire incorporated two scales with three items each: one for positive and another for negative attitudes. In this sense, levels of agreement and disagreement on both scales were measured as indicators of the increase or decrease in the positive and negative attitudes towards STEM. Figure 1 shows the data for the positive attitude scale in Spain and the UK.

As shown in figure 1, all three indicators were slightly more positive in the Spanish case study after delivery of the PERSEIA. Conversely, science busking in the 
UK only achieved the goal of increasing positive attitudes for one of the indicators; meanwhile, both agreement and disagreement decreased for "Scientific knowledge is important for my future career" after the PERSEIA, meaning that students became more neutral on the question, and disagreement with the sentence "If I wanted to, I could be a scientist" increased after the PERSEIA.

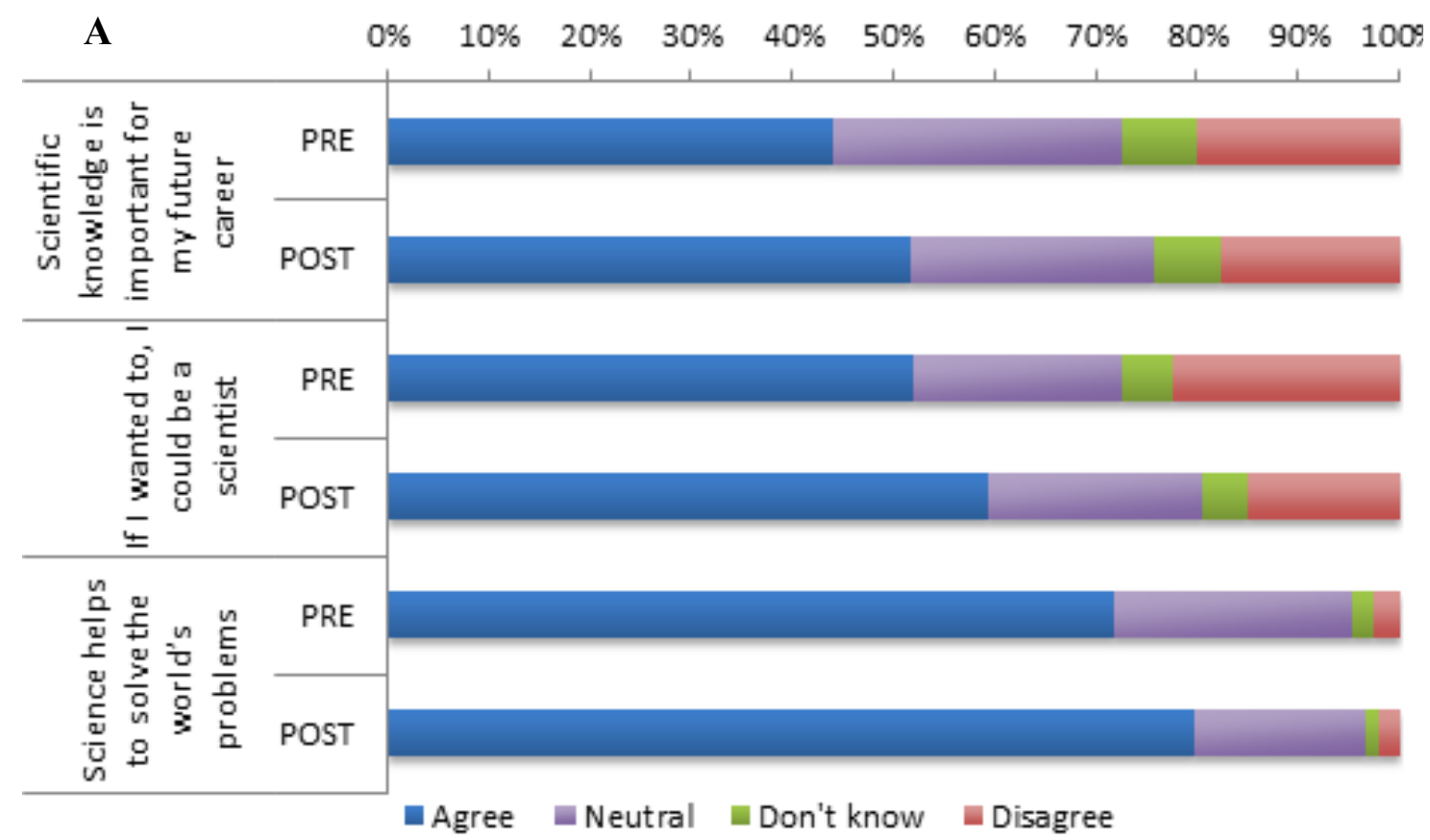




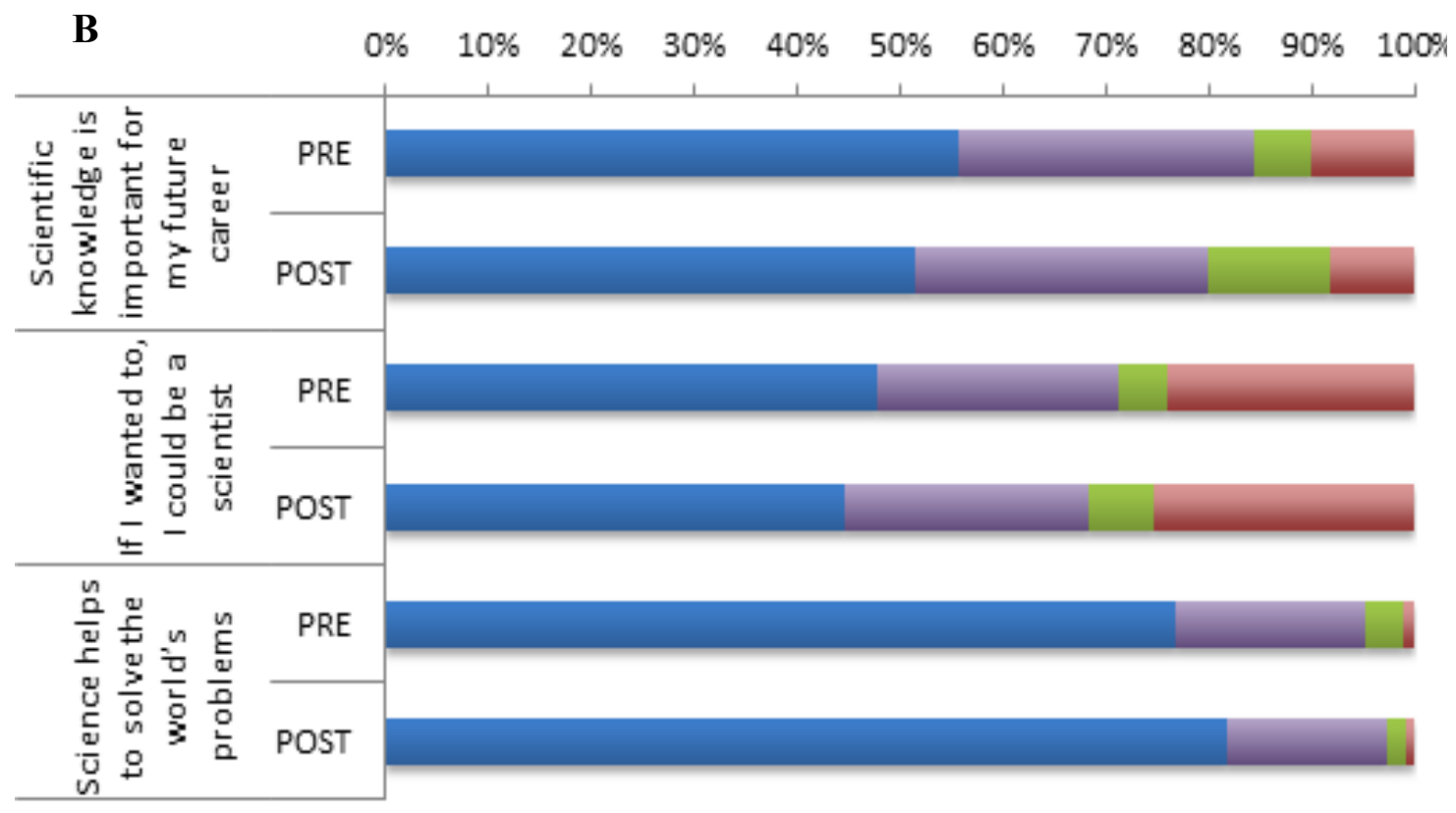

- Agree Neutral Don't know Disagree

Figure 1: Graph showing percentage of agreement, disagreement, and neutrality in relation to positive attitudes towards STEM pre- and post-PERSEIA in Spain (A) and UK (B).

The results of both case studies were analysed by gender to see whether there were meaningful differences between boys and girls in relation to positive attitudes towards STEM subjects and jobs. In Spain (table 3) there were no meaningful differences except for the indicator "Scientific knowledge is important for my future career", for which there was a much higher increase in agreement among boys than among girls (12\% vs. $3.3 \%)$. This suggests that major efforts are needed in future PERSEIA to highlight the value of STEM for girls' careers.

In the UK case (table 4), a remarkable difference between boys and girls can be appreciated in relation to attitudes towards STEM careers. For the indicator "If I wanted to, I could be a scientist", girls' degree of agreement decreased after the PERSEIA by $11.7 \%$ while boys' increased by $4.7 \%$, i.e. there is a difference between them of more than $15 \%$. As in the Spanish case, major efforts are needed in future PERSEIA to highlight the value of STEM careers amongst girls. 
Table 3: Agreement, disagreement, and neutrality in relation to positive attitudes towards STEM in Spain, by gender.

\begin{tabular}{|c|c|c|c|c|c|c|c|c|c|c|}
\hline & & \multicolumn{3}{|c|}{ Agree } & \multicolumn{3}{|c|}{ Disagree } & \multicolumn{3}{|c|}{ Neutral } \\
\hline & & PRE & POST & DIF & PRE & POST & DIF & PRE & POST & DIF \\
\hline \multirow{3}{*}{$\begin{array}{l}\text { Scientific knowledge is important for } \\
\text { my future career }\end{array}$} & ALL & $43.9 \%$ & $51.6 \%$ & $7.7 \%$ & $20.2 \%$ & $17.7 \%$ & $-2.5 \%$ & $28.6 \%$ & $24.1 \%$ & $-4.5 \%$ \\
\hline & BOYS & $42.8 \%$ & $54.8 \%$ & $12.0 \%$ & $15.0 \%$ & $14.4 \%$ & $-0.6 \%$ & $34.9 \%$ & $25.9 \%$ & $-9.0 \%$ \\
\hline & GIRLS & $45.1 \%$ & $48.4 \%$ & $3.3 \%$ & $25.2 \%$ & $21.1 \%$ & $-4.1 \%$ & $22.4 \%$ & $22.3 \%$ & $-0.1 \%$ \\
\hline \multirow[t]{3}{*}{ If I wanted to, I could be a scientist } & ALL & $51.8 \%$ & $59.4 \%$ & $7.6 \%$ & $22.5 \%$ & $15.1 \%$ & $-7.4 \%$ & $20.7 \%$ & $21.0 \%$ & $0.3 \%$ \\
\hline & BOYS & $54.4 \%$ & $60.7 \%$ & $6.3 \%$ & $22.6 \%$ & $14.7 \%$ & $-7.9 \%$ & $19.3 \%$ & $18.9 \%$ & $-0.4 \%$ \\
\hline & GIRLS & $49.4 \%$ & $58.1 \%$ & $8.7 \%$ & $22.4 \%$ & $15.3 \%$ & $-7.1 \%$ & $21.9 \%$ & $23.2 \%$ & $1.3 \%$ \\
\hline \multirow{3}{*}{$\begin{array}{l}\text { Science helps to solve the world's } \\
\text { problems }\end{array}$} & ALL & $71.7 \%$ & $79.5 \%$ & $7.8 \%$ & $2.6 \%$ & $2.2 \%$ & $-0.4 \%$ & $23.4 \%$ & $17.0 \%$ & $-6.4 \%$ \\
\hline & BOYS & $70.5 \%$ & $77.5 \%$ & $7.0 \%$ & $1.8 \%$ & $1.6 \%$ & $-0.2 \%$ & $25.6 \%$ & $18.8 \%$ & $-6.8 \%$ \\
\hline & GIRLS & $73.1 \%$ & $81.4 \%$ & $8.3 \%$ & $3.5 \%$ & $2.9 \%$ & $-0.6 \%$ & $21.1 \%$ & $15.3 \%$ & $-5.8 \%$ \\
\hline
\end{tabular}

Table 4: Agreement, disagreement, and neutrality in relation to positive attitudes towards STEM in UK, by gender.

\begin{tabular}{|c|c|c|c|c|c|c|c|c|c|c|}
\hline & & \multicolumn{3}{|c|}{ Agree } & \multicolumn{3}{|c|}{ Disagree } & \multicolumn{3}{|c|}{ Neutral } \\
\hline & & PRE & POST & DIF & PRE & POST & DIF & PRE & POST & DIF \\
\hline \multirow{3}{*}{$\begin{array}{l}\text { Scientific knowledge is important for } \\
\text { my future career }\end{array}$} & ALL & $55.7 \%$ & $51.3 \%$ & $-4.4 \%$ & $10.2 \%$ & $8.3 \%$ & $-1.9 \%$ & $28.6 \%$ & $28.4 \%$ & $-0.2 \%$ \\
\hline & BOYS & $59.4 \%$ & $51.7 \%$ & $-7.7 \%$ & $7.3 \%$ & $8.6 \%$ & $1.3 \%$ & $28.1 \%$ & $29.3 \%$ & $1.2 \%$ \\
\hline & GIRLS & $51.7 \%$ & $51.0 \%$ & $-0.7 \%$ & $13.5 \%$ & $7.8 \%$ & $-5.7 \%$ & $29.2 \%$ & $27.5 \%$ & $-1.7 \%$ \\
\hline \multirow[t]{3}{*}{ If I wanted to, I could be a scientist } & ALL & $47.6 \%$ & $44.5 \%$ & $-3.1 \%$ & $24.0 \%$ & $25.4 \%$ & $1.4 \%$ & $23.5 \%$ & $23.6 \%$ & $0.1 \%$ \\
\hline & BOYS & $41.8 \%$ & $46.5 \%$ & $4.7 \%$ & $25.5 \%$ & $25.9 \%$ & $0.4 \%$ & $27.6 \%$ & $25.9 \%$ & $-1.7 \%$ \\
\hline & GIRLS & $54.0 \%$ & $42.3 \%$ & $-11.7 \%$ & $22.5 \%$ & $25.0 \%$ & $2.5 \%$ & $19.1 \%$ & $21.2 \%$ & $2.1 \%$ \\
\hline \multirow{3}{*}{$\begin{array}{l}\text { Science helps to solve the world's } \\
\text { problems }\end{array}$} & ALL & $76.6 \%$ & $81.7 \%$ & $5.1 \%$ & $1.1 \%$ & $0.9 \%$ & $-0.2 \%$ & $18.6 \%$ & $15.6 \%$ & $-3.0 \%$ \\
\hline & BOYS & $77.5 \%$ & $86.3 \%$ & $8.8 \%$ & $2.0 \%$ & $0.0 \%$ & $-2.0 \%$ & $16.3 \%$ & $12.1 \%$ & $-4.2 \%$ \\
\hline & GIRLS & $75.6 \%$ & $76.4 \%$ & $0.8 \%$ & $0.0 \%$ & $2.0 \%$ & $2.0 \%$ & $21.1 \%$ & $19.6 \%$ & $-1.5 \%$ \\
\hline
\end{tabular}


In addition to positive attitudes, indicators for negative attitudes towards science were also assessed after delivering the PERSEIA. In Spain, negative attitudes decreased in all three indicators of the scale (Fig. 2-A). In contrast, in the UK the indicators for negative attitudes increased, except for the indicator "Science is usually boring" (Fig. 2B). As was done with the positive attitude responses, the results of the Spanish and UK case studies were disaggregated by gender to examine whether there were meaningful differences between boys and girls in relation to negative attitudes towards STEM subjects and jobs.

In Spain (table 5), all three indicators showed that negative attitudes decreased for both genders, but more acutely among boys than girls. In fact, girls' level of disagreement with the negative indicator "Science is not for me" decreased by $4.7 \%$ after having participated in the PERSEIA. In the UK case study (table 6), on the other hand, only the level of agreement with the indicator "Science is usually boring" decreased after the PERSEIA, while the other two negative indicators increased. In this case, girls were less prone to changing their negative attitude than boys. 

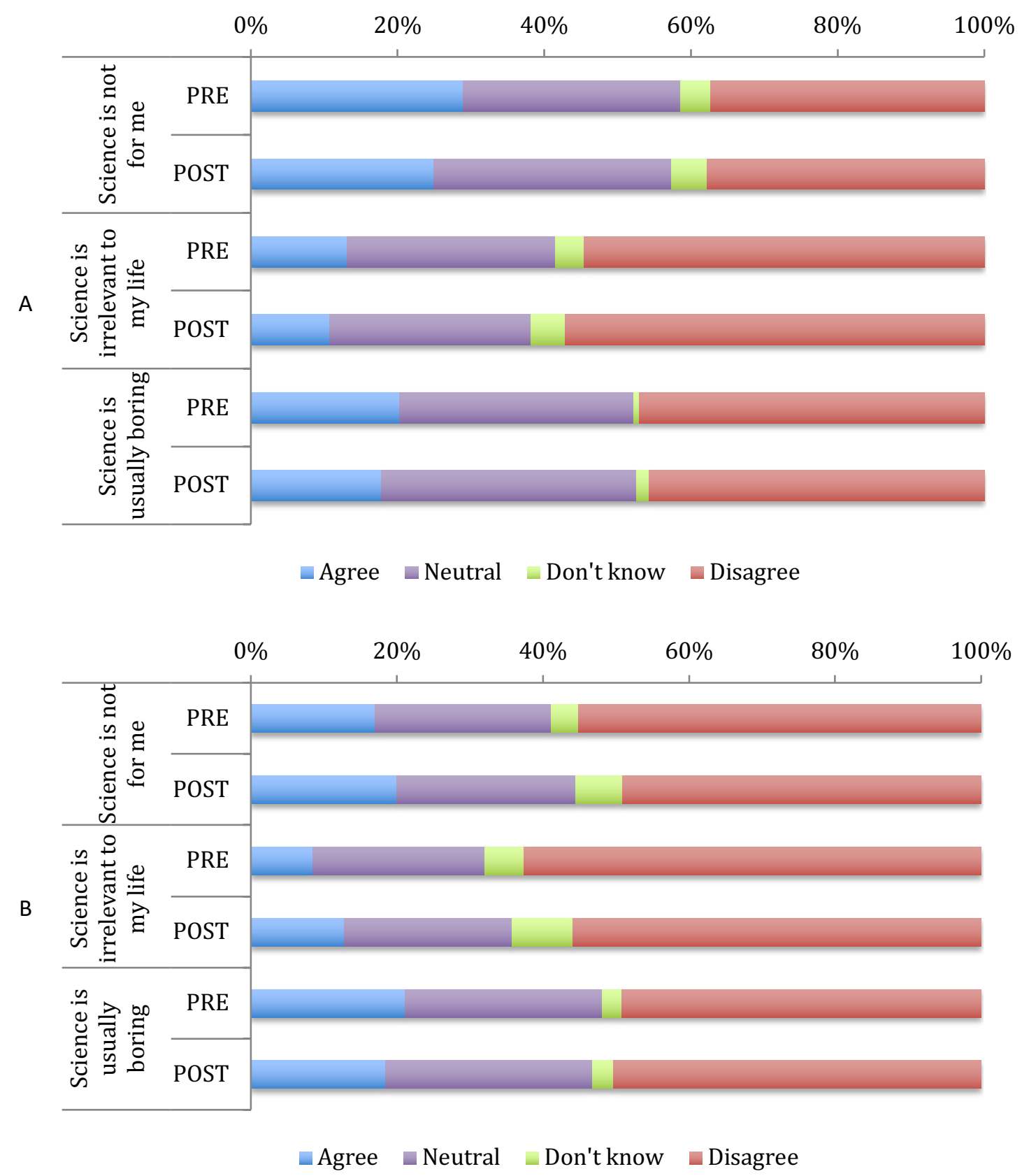

Figure 2: Percentage of agreement, disagreement, and neutrality in relation to negative attitudes towards STEM pre- and post-PERSEIA in Spain (A) and UK (B). 
Table 5: Agreement, disagreement, and neutrality in relation to positive attitudes towards STEM in Spain, by gender.

\begin{tabular}{|c|c|c|c|c|c|c|c|c|c|c|}
\hline & & \multicolumn{3}{|c|}{ Agree } & \multicolumn{3}{|c|}{ Disagree } & \multicolumn{3}{|c|}{ Neutral } \\
\hline & & PRE & POST & DIF & PRE & POST & DIF & PRE & POST & DIF \\
\hline \multirow[b]{3}{*}{ Science is not for me } & ALL & $28.9 \%$ & $23.2 \%$ & $-5.7 \%$ & $37.3 \%$ & $35.2 \%$ & $-2.1 \%$ & $29.7 \%$ & $30.2 \%$ & $0.5 \%$ \\
\hline & BOYS & $31.2 \%$ & $23.5 \%$ & $-7.7 \%$ & $36.9 \%$ & $37.1 \%$ & $0.2 \%$ & $28.0 \%$ & $31.3 \%$ & $3.3 \%$ \\
\hline & GIRLS & $26.7 \%$ & $22.8 \%$ & $-3.9 \%$ & $37.9 \%$ & $33.2 \%$ & $-4.7 \%$ & $31.1 \%$ & $29.0 \%$ & $-2.1 \%$ \\
\hline \multirow[b]{3}{*}{ Science is irrelevant to my life } & ALL & $13.1 \%$ & $10.7 \%$ & $-2.4 \%$ & $54.6 \%$ & $57.1 \%$ & $2.5 \%$ & $28.5 \%$ & $27.4 \%$ & $-1.1 \%$ \\
\hline & BOYS & $14.7 \%$ & $10.2 \%$ & $-4.5 \%$ & $50.0 \%$ & $54.7 \%$ & $4.7 \%$ & $31.7 \%$ & $30.6 \%$ & $-1.1 \%$ \\
\hline & GIRLS & $11.6 \%$ & $11.3 \%$ & $-0.3 \%$ & $59.1 \%$ & $59.6 \%$ & $0.5 \%$ & $25.3 \%$ & $24.2 \%$ & $-1.1 \%$ \\
\hline \multirow[b]{3}{*}{ Science is usually boring } & ALL & $20.3 \%$ & $17.8 \%$ & $-2.5 \%$ & $47.0 \%$ & $45.8 \%$ & $-1.2 \%$ & $31.9 \%$ & $34.8 \%$ & $2.9 \%$ \\
\hline & BOYS & $22.6 \%$ & $18.6 \%$ & $-4.0 \%$ & $44.5 \%$ & $43.0 \%$ & $-1.5 \%$ & $31.3 \%$ & $36.8 \%$ & $5.5 \%$ \\
\hline & GIRLS & $18.2 \%$ & $17.0 \%$ & $-1.2 \%$ & $49.5 \%$ & $48.6 \%$ & $-0.9 \%$ & $32.3 \%$ & $32.8 \%$ & $0.5 \%$ \\
\hline
\end{tabular}

Table 6: Agreement, disagreement, and neutrality in relation to positive attitudes towards STEM in UK, by gender.

\begin{tabular}{|c|c|c|c|c|c|c|c|c|c|c|}
\hline & & \multicolumn{3}{|c|}{ Agree } & \multicolumn{3}{|c|}{ Disagree } & \multicolumn{3}{|c|}{ Neutral } \\
\hline & & PRE & POST & DIF & PRE & POST & DIF & PRE & POST & DIF \\
\hline \multirow[b]{3}{*}{ Science is not for me } & ALL & $17.2 \%$ & $20.0 \%$ & $2.8 \%$ & $55.7 \%$ & $49.1 \%$ & $-6.6 \%$ & $24.3 \%$ & $24.5 \%$ & $0.2 \%$ \\
\hline & BOYS & $20.8 \%$ & $22.4 \%$ & $1.6 \%$ & $57.3 \%$ & $48.3 \%$ & $-9.0 \%$ & $20.8 \%$ & $24.1 \%$ & $3.3 \%$ \\
\hline & GIRLS & $13.4 \%$ & $17.3 \%$ & $3.9 \%$ & $53.9 \%$ & $50.0 \%$ & $-3.9 \%$ & $28.1 \%$ & $25.0 \%$ & $-3.1 \%$ \\
\hline \multirow[b]{3}{*}{ Science is irrelevant to my life } & ALL & $8.5 \%$ & $12.8 \%$ & $4.3 \%$ & $62.5 \%$ & $55.9 \%$ & $-6.6 \%$ & $23.5 \%$ & $22.9 \%$ & $-0.6 \%$ \\
\hline & BOYS & $9.2 \%$ & $12.0 \%$ & $2.8 \%$ & $68.4 \%$ & $56.9 \%$ & $-11.5 \%$ & $19.4 \%$ & $22.4 \%$ & $3.0 \%$ \\
\hline & GIRLS & $7.8 \%$ & $13.7 \%$ & $5.9 \%$ & $56.2 \%$ & $54.9 \%$ & $-1.3 \%$ & $28.1 \%$ & $23.5 \%$ & $-4.6 \%$ \\
\hline \multirow[b]{3}{*}{ Science is usually boring } & ALL & $21.1 \%$ & $18.4 \%$ & $-2.7 \%$ & $49.2 \%$ & $50.4 \%$ & $1.2 \%$ & $27.0 \%$ & $28.4 \%$ & $1.4 \%$ \\
\hline & BOYS & $18.6 \%$ & $17.2 \%$ & $-1.4 \%$ & $47.4 \%$ & $48.3 \%$ & $0.9 \%$ & $29.9 \%$ & $31.0 \%$ & $1.1 \%$ \\
\hline & GIRLS & $23.8 \%$ & $19.6 \%$ & $-4.2 \%$ & $51.1 \%$ & $52.9 \%$ & $1.8 \%$ & $23.9 \%$ & $25.5 \%$ & $1.6 \%$ \\
\hline
\end{tabular}


In order to determine how students perceive ethical concerns related to scientific activity, the questionnaire included a 2-item Likert scale. As in the previous figures, figure 3 shows the degrees of agreement and disagreement with these two items in the two case studies analysed. In this case, the option "Don't know" is included, as its results are relevant for the study.

In the Spanish case study, both indicators saw an increase in agreement after the PERSEIA, especially "Scientists follow ethical standards to pursue their studies", which increased by more than $10 \%$. It is also remarkable that the "Don't know" answers decreased by $5 \%$. There are no meaningful differences between genders in the perceptions of ethical concerns regarding scientific practice.

In the UK, ethical perceptions were also more positive after the PERSEIA. In this case, however, the ratio of respondents choosing the option "Don't know" was higher than in Spain and increased after the PERSEIA, reinforcing the idea that the science busking show, as a tool for transmitting RRI values, must be reformulated. There were no meaningful differences between girls and boys in their perceptions of ethical concerns.

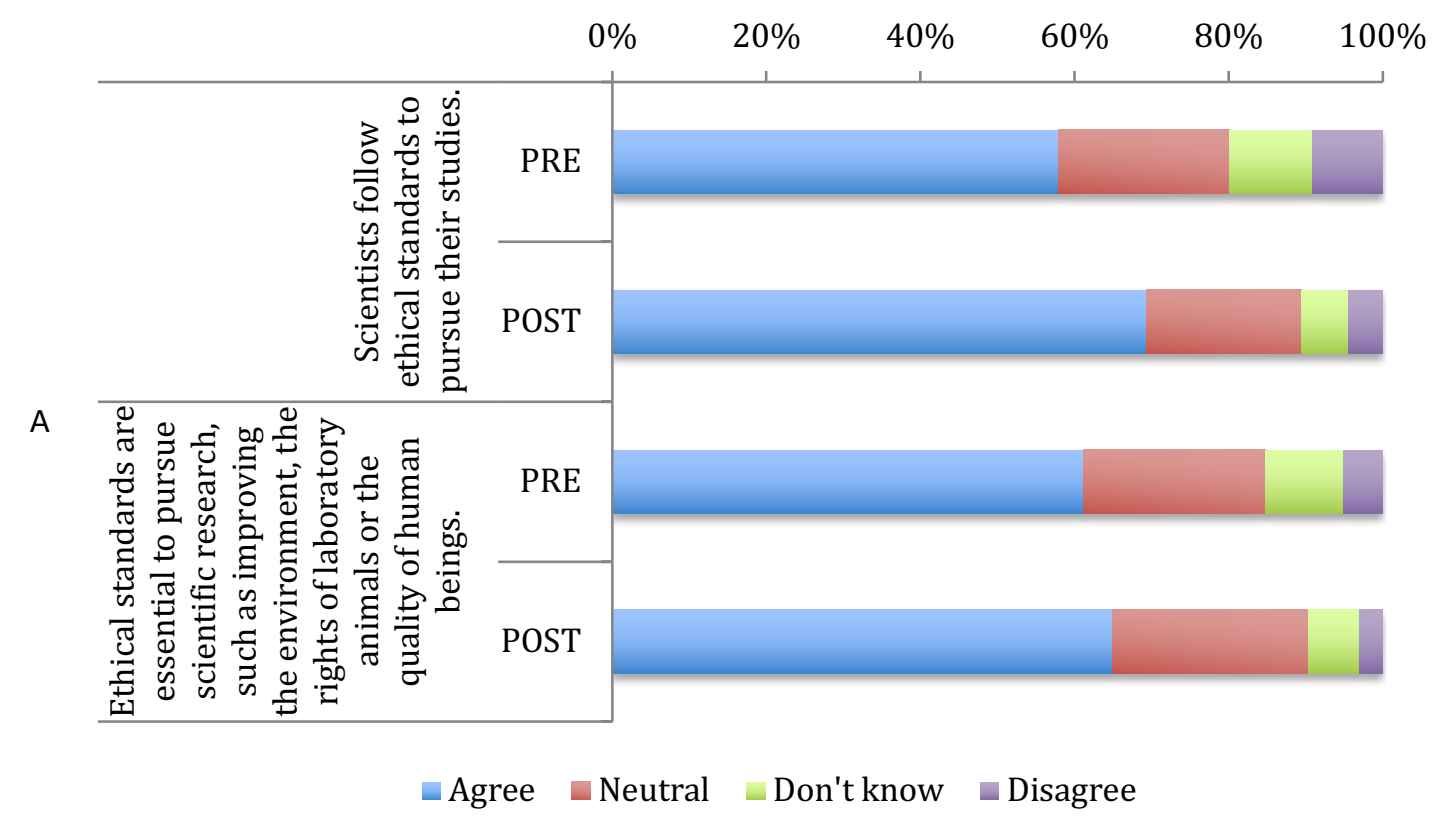




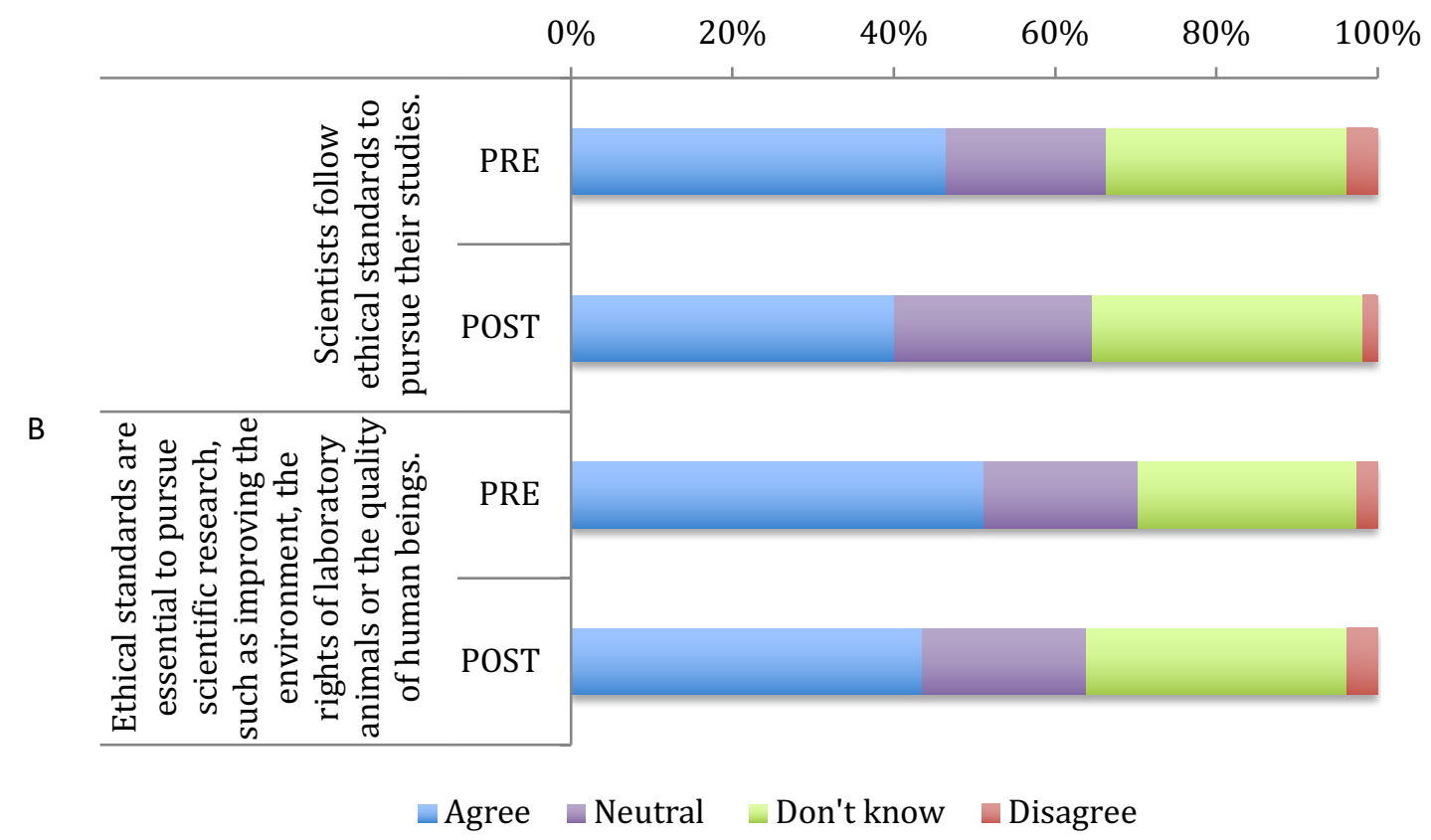

Figure 3: Graphs showing the percentage of agreement, disagreement, neutrality and "Don't know" option in relation to ethical issues concerning science pre- and post-PERSEIA in Spain (A) and UK (B).

Students' perceptions of science-related gender issues

In order to determine the extent to which students perceive science as a gendered pursuit, pre- and post-surveys included two indicators related to this topic. The first asked how many female scientists they knew. Out of their responses, only the names of "real" female scientists were counted. The second indicator evaluated how gendered they considered six different professions related to science: veterinarian, computer programmer, theoretical physicist, nurse, astronomer, and engineer. 


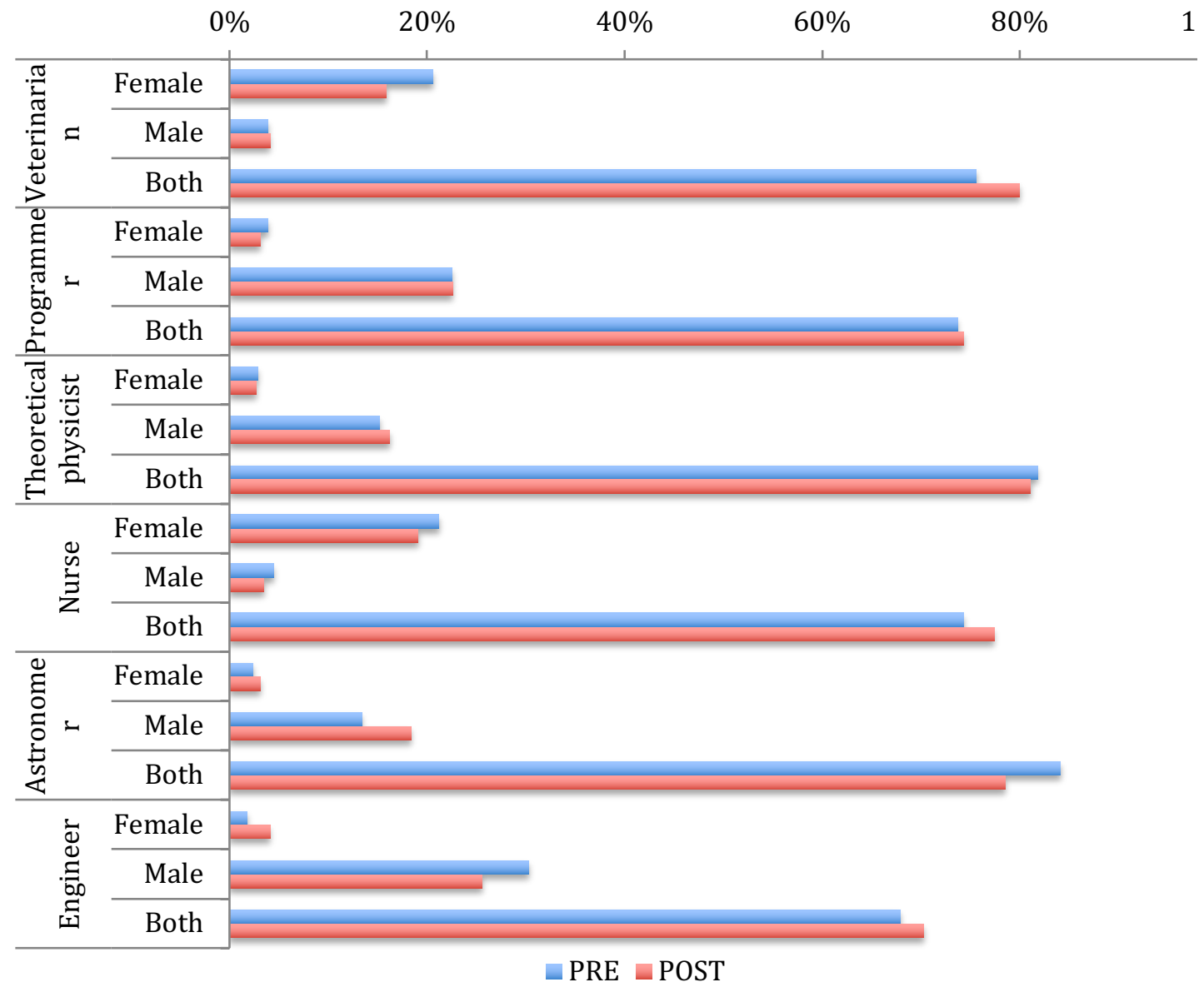

Figure 4: Gendered perceptions towards six scientific professions in Spain.

In Spain, $85.1 \%$ of the students who took the pre-PERSEIA survey did not know any female scientist, and this level decreased to $82.9 \%$ after delivering the PERSEIA. In relation to how gendered they perceived each of the six professions, figure 4 shows that in general they perceived all of them as being able to be performed by both men and women. However, veterinarian and nurse were slightly more associated with women whereas programmer, theoretical physicist and astronomer were more perceived as men's jobs. After the PERSEIA, the perception that these professions could be carried out by both men and women increased for all cases except for the astronomer, which was even more associated with men in the post-PERSEIA survey. 


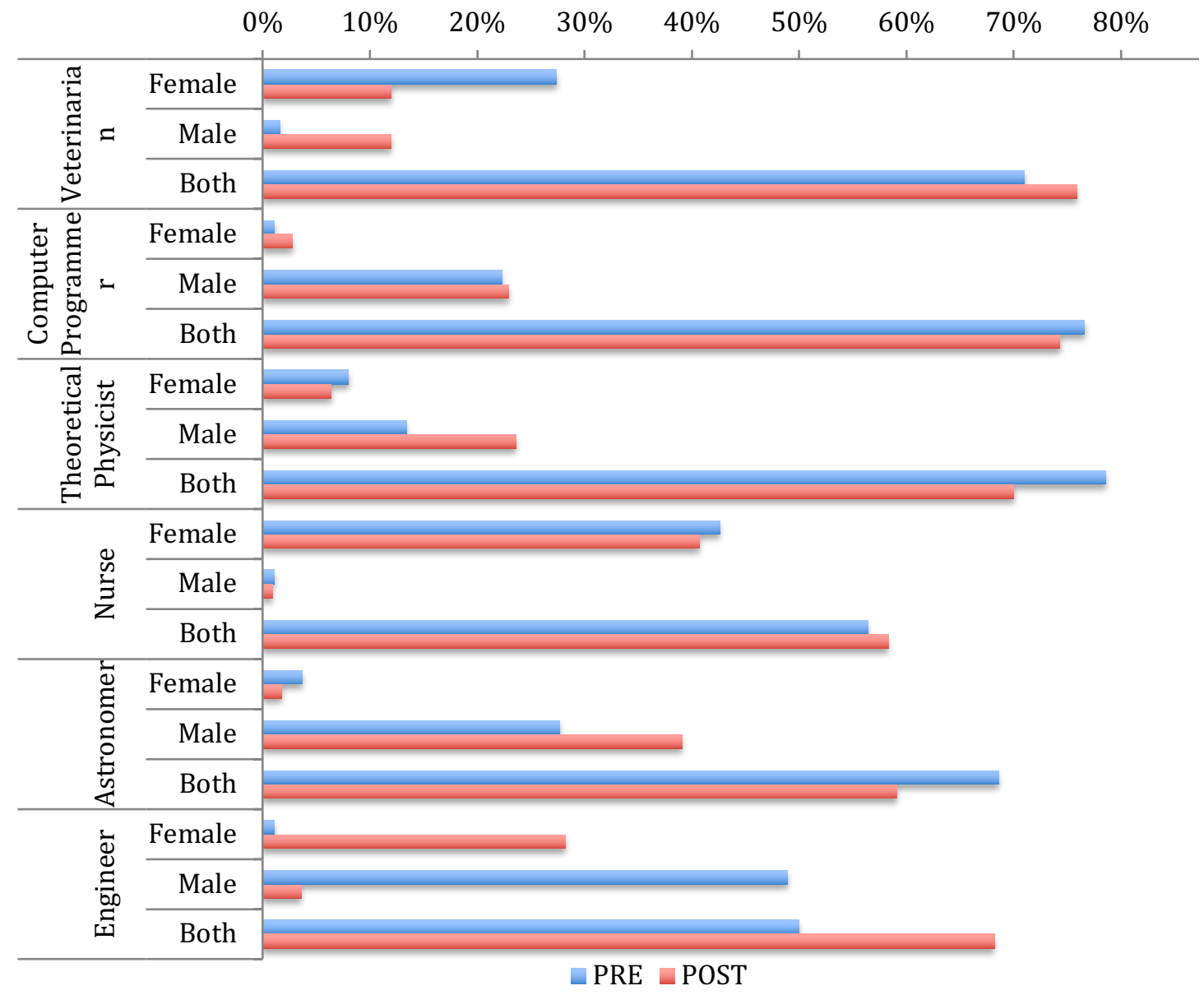

Figure 5: Gendered perceptions towards six scientific professions in UK.

In the UK, $88.8 \%$ of the students taking the pre-PERSEIA survey did not know any female scientist, and this proportion increased very slightly to $89.2 \%$ after the PERSEIA. The gendering pattern was also very similar to Spain, with more than $70 \%$ of students agreeing that all six professions could be performed by both women and men equally. Nevertheless, veterinarian and nurse were perceived as more associated with women than men, in the latter case with more than $40 \%$ seeing it as a woman's job, whereas the other four were perceived as more associated with men. These patterns did not change much after the PERSEIA except for the engineer, as there was a $25 \%$ in the perception of women as engineers. The results are shown in figure 5. 
In addition to the analysis of RRI values and STEM perceptions shown above, the PERSEIA evaluation strategy included an assessment of performance styles through the post-PERSEIA survey using three different scales: positive perceptions, negative perceptions, and general recommendations. This last scale assessed the impact that the general recommendations in the guidelines had on the general development of the PERSEIA delivery. These scales were complemented by structured interviews with the performers.

In Spain, all indicators of positive perceptions had a level of agreement of more than $60 \%$. However, less than $40 \%$ of students agreed that attending the PERSEIA was positive for their learning of science. In the case of negative perceptions, the level of disagreement was higher than $60 \%$ in all cases, although the scientific monologues were more confusing for boys than for girls. In Spain, only $6.7 \%$ of students did not enjoy the PERSEIA (figure 6), consistent with the results obtained on the statement "The performance was boring", with which $12.4 \%$ of students agreed, and with "The activity was a waste of time", with which only $8.7 \%$ agreed (figure 7 ). The use of monologues to talk about science did not adversely affect the image that students have of the performers, as only $7.8 \%$ of students did not consider the performers to be scientific experts. In the same line, a very small $4.8 \%$ of the students did not trust the scientific information given during the performance and $13.1 \%$ considered it confusing, while $42.0 \%$ considered the performance important for their scientific learning (figure 6).

Showing a video was considered a good idea by more than $65 \%$ of respondents, especially among the girls (figure 6). Moreover, almost 30\% of the students attending the Spanish PERSEIA agreed that they had actively participated in the event. Indeed, $27 \%$ of the students attending the event talked directly to the performers during the event (data not shown). This confirms that significant effort was made to achieve the goal of making the PERSEIA interactive, as stand-up comedy shows normally have minimal interaction with the audience. The use of social networking applications was moderate, with less than $50 \%$ of the audience having used them to interact with the performers (data not shown). All these results are shown in figure 6.6.

In the UK, two of the indicators for positive perceptions ("I enjoyed the performance" and "I trust the scientific information in the performance I attended") had a level of agreement of almost $80 \%$. However, only $50 \%$ of students agreed that "The 
performers are scientific experts". In the case of negative perceptions, the level of disagreement was higher than $70 \%$, although many boys responded neutrally to the question of whether the science busking event was confusing. The level of interaction with the audience was higher than in the Spanish case, with almost $50 \%$ of students stating that they had spoken with the performers and actively participated in the event. This fact could be due to the fact that busking is delivered with smaller audiences than stand-up (table 5.4). Only $40 \%$ of students made use of social networks. All these results can be viewed in figure 7 .

$\begin{array}{llllllllll}0 \% & 10 \% & 20 \% & 30 \% & 40 \% & 50 \% & 60 \% & 70 \% & 80 \% & 90 \%\end{array}$
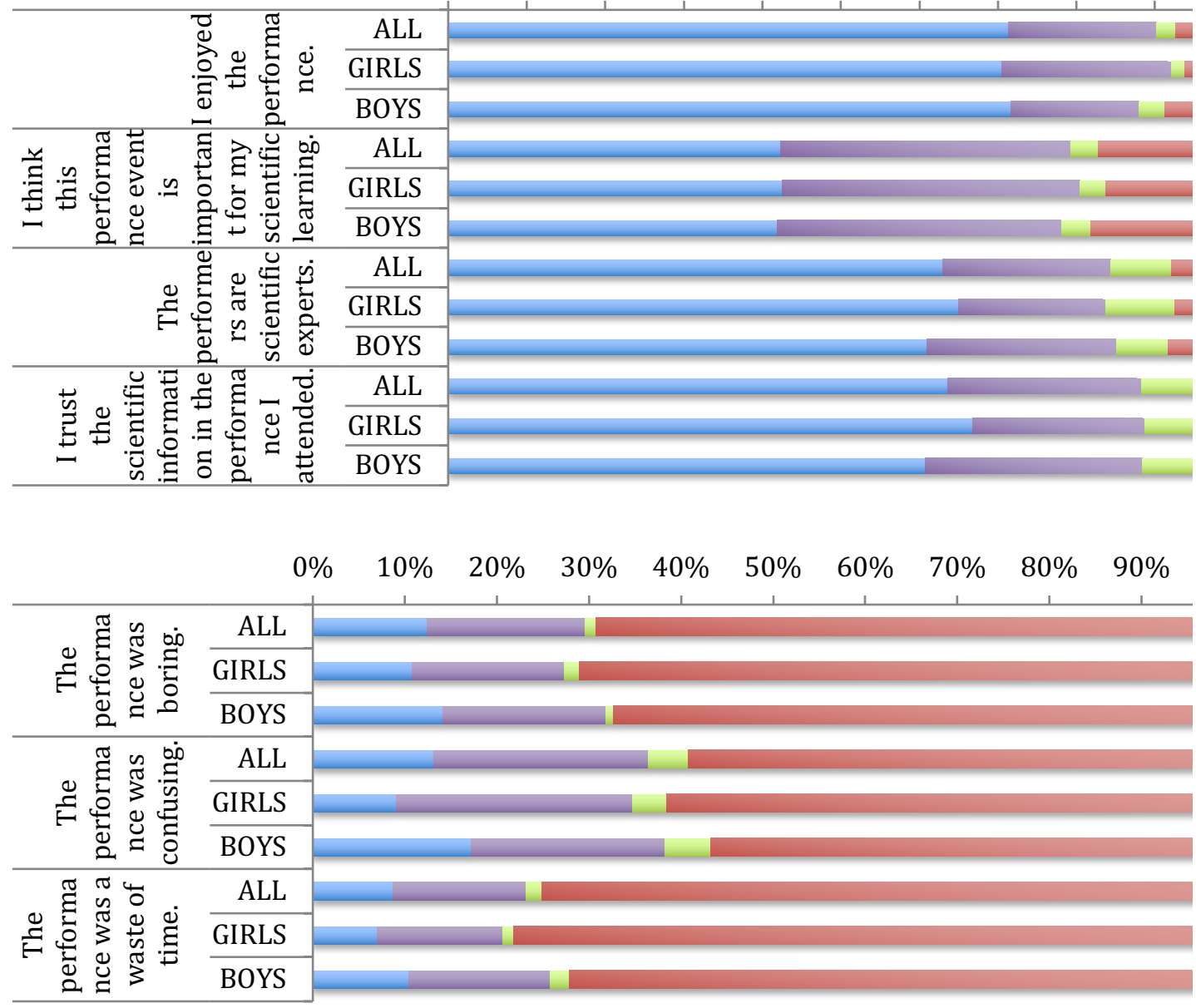
$\begin{array}{lllllllllll}0 \% & 10 \% & 20 \% & 30 \% & 40 \% & 50 \% & 60 \% & 70 \% & 80 \% & 90 \% & 1\end{array}$

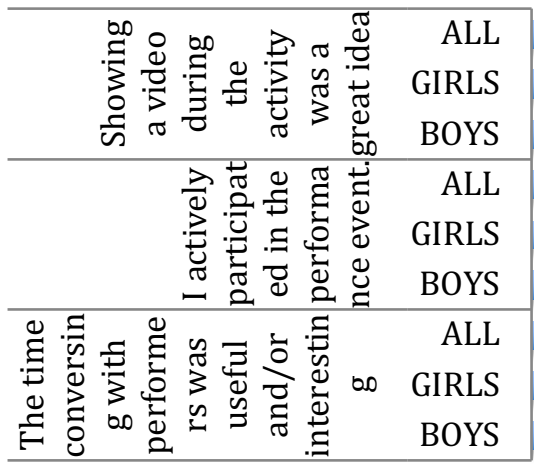

$\square$ Agree $\square$ Neutral $\square$ Don't know $\square$ Disagree

Figure 6: Evaluation of stand-up comedy style performance in Spain, by gender.

$\begin{array}{lllllllllll}0 \% & 10 \% & 20 \% & 30 \% & 40 \% & 50 \% & 60 \% & 70 \% & 80 \% & 90 \% & 100 \%\end{array}$
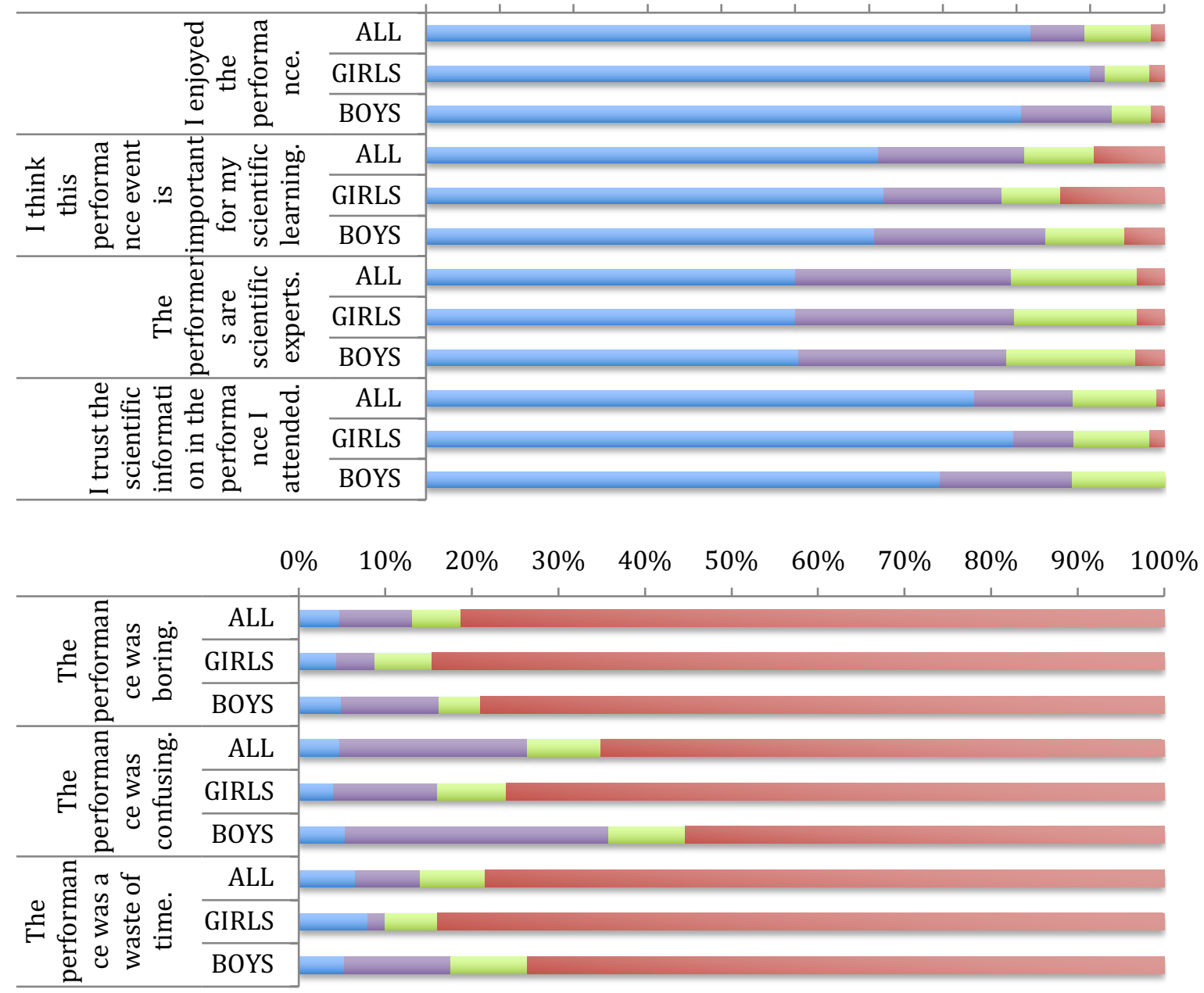


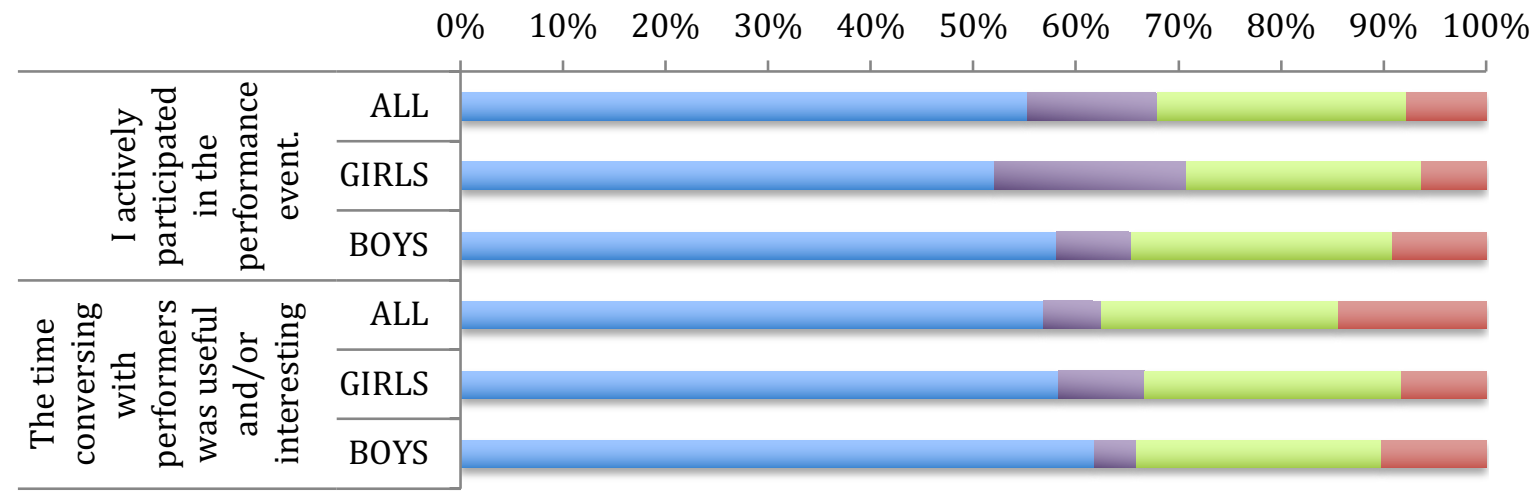

$\square$ Agree $\square$ Neutral $\square$ Don't know $\square$ Disagree

Figure 7: Evaluation of science busking style performance in UK, by gender.

\section{DISCUSSION AND CONCLUSIONS}

PERSEIA resulting from the adaptation of previous performance-based activities were delivered in 9 secondary schools in each country. In total, 2,089 secondary school students attended the PERSEIA shows. Although other assessment protocols have been published elsewhere (Klassen, 2006, Heras and Ruiz-Mallen, 2017), we decided to create a new assessment protocol designed to evaluate the impact of PERSEIA. The evaluation methodology consisting of ex-ante and ex-post surveys has offered sound results that will support the review of the PERSEIA model for future use.

The results reveal that the stand-up comedy PERSEIA delivered in Spain enhanced positive attitudes towards STEM. However, the science busking PERSEIA delivered in the UK did not appear to achieve this goal, as students' attitudes towards STEM did not change after attending the show. The science busking show therefore needs to be reviewed in this respect. Otherwise, both PERSEIA need to make major efforts to improve attitudes towards STEM among girls. Regarding ethical concerns related to research activity, both PERSEIA were effective at addressing these issues. Nevertheless, these results should be considered with caution as they were measured with a scale of only two items, only one of which was reliable. In the same sense, the indicators for awareness of gender differences have not been effective at detecting changes. 
These results suggest that the stand-up comedy activity is more effective than science busking in motivating students to engage with STEM and in challenging stereotypes associated with scientific research. The reasons for this difference can be found, as noted in the introduction, in the dramatic nature of these two art forms. As Quirck (2015) suggests, stand-up comedy has a stronger influence on audiences due to its power to trigger emotions. Stand-up comedians, Quirck argues, "serve an important prosocial function by testing those ideas that we take for granted, but also can coax us into behaving in a way we would not normally countenance." Nevertheless, while stand-up comedy was more effective than science busking at improving student attitudes towards STEM, the science busking show was more interactive, participatory and appealing, both for students and for performers. In this sense, we can conclude that emotional engagement might be more important for debunking stereotypes than interaction and participation.

Our working hypothesis is that arts-based methods help trigger emotions that facilitate the deconstruction of false myths and stereotypes related to scientific research and activity. Our results support this view and suggest that drama-based methods that foster emotional engagement are the most suitable. Very recently, pre-bunking and inoculation has been shown to be effective in reducing susceptibility to fake news related to climate change, proving that emotions and the mobilization of emotional doubts are key to debunking false myths (Banas and Rains, 2010; Lewandowsky et al, 2012; Roozenbeek and van der Linden, 2019). In this regard, our study adds to this line of research and can be viewed as further evidence to support an understanding of the mechanisms needed to change false opinions, myths and stereotypes.

Our study is a first step towards the development of innovative student-centred drama-based teaching activities for STEM directed at secondary school students that can debunk stereotypes and motivate interest. The protocol developed, however, requires further reflection and reinforcement with the views of other relevant stakeholders in science education, such as participating students and teachers. In this respect, further empirical work is needed for re-testing and improvement of both the assessment protocol and the teaching activities. We hope this research can support future studies and, in particular, that it can help secondary teachers improve their 
teaching methodologies and increase their students' motivation to take an interest in STEM.

\section{DECLARATION OF CONFLICTING INTERESTS}

The author(s) declared no potential conflicts of interest with respect to the research, authorship, and/or publication of this article.

\section{FUNDING}

The author(s) disclosed receipt of the following financial support for the research, authorship, and/or publication of this article: This work was supported by the European's Union H2020 research and innovation programme under Grant Agreement No. 665826: PERFORM "Participatory Engagement with Scientific and Technological Research through Performance."

\section{REFERENCES}

Aschbacher, P. R., Li, E., \& Roth, E. J. (2010). Is science me? High school students' identities, participation and aspirations in science, engineering, and medicine. Journal of Research in Science Teaching, 47(5)

Aubusson, P.J., \& Fogwill, S. (2006). Role play as analogical modeling in science. In P.J. Aubusson, A.G. Harrison, \& S.M. Ritchie (Eds.), Metaphor and analogy in science education (pp. 93-104). The Netherlands: Springer.

Bailey, S., \& Watson, R. (1998). Establishing basic ecological understanding in younger pupils: A pilot evaluation of a strategy based on drama/role play. International Journal of Science Education, 20, 139-152.

Banas JA, Rains SA (2010) A meta-analysis of research on inoculation theory. Communication Monographs; 77(3), 281-311

Baraúna Teixeira, T., Motos Teruel, T. (2009) De Freire a Boal. Pedagogía del Oprimido, Teatro del Oprimido. Naque Editora: Madrid, Spain

Barone, T., Eisner, E. (2012) Arts-based educational research. SAGE Publications: Thousand Oaks.

Convert, B. and Gugenheim, F. (2005) Scientific Vocations in Crisis in France: Explanatory Social Developments and Mechanisms. European Journal Vocational Training, 35, 12-20.

Dorion, K. R. (2009) Science through drama: A multiple case exploration of the characteristics of drama activities used in secondary science lessons. International Journal of Science Education, 31(16), 2247-2270.

Dopico, E, García-Vázquez, E, Alonso, C, Váquez, E (2015) Didáctica de las ciencias a través del teatro. Revista Iberoamericana de Educación, 69(3): 117-132

Eccles, J. S. (1994), Understanding Women's Educational and Occupational Choices. Psychology of Women Quarterly, 18: 585-609

European Comission. (2015). Science Education for Responsible Citizenship. Report to the European Commission of the expert group on science education. 
Luxembourg: Publications Office of the European Union.

Flash Eurobarometer (2008). Young people and science, series $n$ 239. The Gallup Organisation

Francis, B. (2002) 'Is the future really female? The impact and implications of gender for 14-16 year olds' career choices', Journal of Education and Work, 15: 7587.

Fouad, NA., Hackett, G., Smith, PL., Kantamneni, N., Fitzpatrick, M., Haag, S and Spencer, D. (2010) Barriers and Supports for Continuing in Mathematics and Science: Gender and Educational Level Differences. Journal of Vocational Behavior 77: 361-373

Heras, M and Ruiz-Mallén, I (2017) Responsible research and innovation indicators for science education assessment: how to measure the impact?, International Journal of Science Education, 39(18): 2482-2507

Jenkins, EW and Nelson, NW (2005) Important but not for me: students' attitudes towards secondary school science in England, Research in Science \& Technological Education, 23(1):41-5

Kahle, J. B., Parker, L. H., Rennie, L. J., \& Riley, D. (1993). Gender differences in science education: Building a model. Educational Psychologist, 28, 379-404.

Klassen, S. (2006). Contextual assessment in science education: Background, issues, and policy. Science Education, 90, 820-851.

Leavy, P. (2009) Method meets art: Arts-based research practice, The Guilford Press, New York.

Leavy, P. (2015) Method meets art: Arts-based research practice. Guilford Publications.

Lee, B. K., Patall, E. A., Cawthon, S. W., \& Steingut, R. R. (2015). The Effect of Drama-Based Pedagogy on PreK-16 Outcomes: A Meta-Analysis of Research From 1985 to 2012. Review of Educational Research, 85(1), 3-49.

Lewandowsky S, Ecker UKH, Seifert CM, Schwarz N, Cook J. Misinformation and its correction-Continued influence and successful debiasing. Psychological Science in the Public Interest. 2012; 13(3)

Littledyke, M. (2008) Science education for environmental awareness: Approaches to integrating cognitive and affective domains. Environmental Education Research,14 (1), 1-17.

McNaughton, M. J. (2004) Educational drama in the teaching of education for sustainability. Environmental Education Research, 10(2), 139-155.

Metcalfe, R.J.A., Abbott, S., Bray, P., Exley, J., Wisnia, D. 1984. Teaching science through drama: an empirical investigation. Research in Science \& Technological Education, 2, 77- 81.

Nicholson H. (2005) Applied drama. Theatre and Performance Practices. Palgrave Macmillan, Basingstoke.

Osborne J, Dillon, J (2008) Science Education in Europe: critical reflections. London: The Nuffield Foundation

Owen, R. Macnaghten, P and Stilgoe, J (2012) Responsible research and innovation: From science in society to science for society, with society, Science and Public Policy, 39(6): 751-76

Ødegaard, M. (2003) Dramatic science. A critical review of drama in science education. Studies in Science Education, 39, 75-101

Rathwell, KJ and Armitage, D (2016). Art and artistic processes bridge knowledge 
systems about social-ecological change: An empirical examination with Inuit artists from Nunavut, Canada. Ecology and Society 21(2): art21

Regan, E., \&and DeWitt, J. (2015). Attitudes, interest and factors influencing STEM enrolment behaviour: An overview of relevant literature. In E. K. Henriksen, J. Dillon, \& J. Ryder (Eds.), Understanding student participation and choice in science and technology education (pp. 63-88)

Riegle-Crumb, C., Moore, C., Ramos-Wada, A (2011) Who Wants to Have a Career in Science or Math? Exploring Adolescents' Future Aspirations by Gender and Race/Ethnicity. Science Education, 2011, 95(3), 458-476

Rocard, M, Csermely, P., Jorde, D., Lenzen, D., Walwerg, H., and Hemmo, V (2007) Science Education Now: A renewed pedagogy for the Future of Europe. European Commission.

Roozenbeek, J., van der Linden, S. (2019) Fake news game confers psychological resistance against online misinformation. Palgrave Commun 5, 65

Ruiz-Mallen, I., Gallois, S., Heras, M. (2018) From White Lab Coats and Crazy Hair to Actual Scientists: Exploring the Impact of Researcher Interaction and Performing Arts on Students' Perception and Motivation for Science. Science Communication, 40(6): 749-777

OECD Organisation for Economic Co-operation and Development (Global Science Forum) (2008). Evolution of Student Interest in Science and Technology Studies Policy Report

Quirck, S (2015) Why Stand-up Matters: How Comedians Manipulate and Influence. London: Bloomsbury.

Sainz, M. (2011). Factors which influence girls' orientations to ICT subjects in schools. Evidence from Spain. International Journal of Gender, Science and Technology, 3(2), 387-406.

Shen, C, Ratan, R, Cai, D and Leavitt, A (2016) Do Men Advance Faster Than Women? Debunking the Gender Performance Gap in Two Massively Multiplayer Online Games, Journal of Computer-Mediated Communication, 21(4): 312-329,

Sheldrake, R (2016) Differential predictors of under-confidence and over-confidence for mathematics and science students in England. Learning and Individual Differences 49: 305-313

Simons, S (2011) Process drama and sex education: Advocating for drama-based components of adolescent health initiatives. Journal of Applied Arts \& Health, 2(2): 113-123.

Sjøberg, Svein and Schreiner, Camilla (2007). Perceptions and images of science and science education. M. Claessens (Ed.) Communicating European Research 2005. Dordrecht: Springer.

St Clair, R. and Benjamin, A. (2011), Performing desires: The dilemma of aspirations and educational attainment. British Educational Research Journal, 37: 501-517

Varelas, M., Pappas, C.C., Tucker-Raymond, E., Kane, J., Hankes, J., Ortiz, I., \& Keblawe-Shamah, N. (2010). Drama activities as ideational resources for primary-grade children in urban science classrooms. Journal of Research in Science Teaching, 47, 302-325.

Tveita J. (1998) Can untraditional learning methods used in physics help girls to be more interested and achieve more in this subject? In E. Torracca (Ed.) Research in Science Education in Europe (pp.1-7). Dordrecht: Kluwer. 
